\title{
The Development of a Model for Geodesic Learning: The Geodesic Information Processing Model
}

\author{
Caroline M. Leaf, Brenda Louw and Isabel Uys \\ Department of Communication Pathology and Audiology \\ University of Pretoria
}

\begin{abstract}
The current article suggests that alternatives to the current traditional learning methods are essential if learning institutions are to provide people with effective life skills that enable them to be autonomous learners. This suggestion is based on a body of literature on alternative learning which stresses the need for fundamental change and hence, a paradigm shift in the perception of learning in order to cope with the world-wide information explosion. The alternative non-traditional approach proposed is geodesic learning which stresses learning how to learn and self-directed inquiry as essential life-skills which enable systems as well as the people in the systems to bring about their own transformation in response to changing situations and requirements. The current article discusses an alternative service delivery model, the geodesic information processing model, which falls within the realms of the geodesic philosophy. The implications of this alternative approach for the speech-language therapist are discussed.
\end{abstract}

\section{OPSOMMING}

Hierdie artikel voer aan dat alternatiewe benaderings tot die huidige tradisionele leermetodes essensiëel is indien onderriginstansies individue met effektiewe lewenslange vaardighede wil toerus wat hulle in staat stel om as onafhanklike leerders te funksioneer. Hierdie voorstel berus op literatuurbewyse oor alternatiewe leermetodes wat die behoefte aan fundamentele verandering beklemtoon, en gevolglik ' $n$ paradigmatiese verskuiwing voorstaan in die persepsies van leer om die wêreld-wye inligtingsontploffing te kan hanteer. Die alternatiewe nie-tradisionele benadering wat voorgestel word, is die geodetiese benadering wat leer hoe om te leer beklemtoon, sowel as self.gerigte navraag as essensiële lewensvaardigheid wat sisteme, en persone binne die sisteme, in staat stel om hulle eie tranformasie te bewerkstellig in respons op veranderende situasies en vereistes. Die huidige artikel bespreek 'n alternatiewe diensleweringsmodel, naamlik die geodetiese inligtingsprosesseringsmodel, wat binne die vakgebied van geodetiese filosofie val. Die implikasies van hierdie alternatiewe benadering vir die spraak-taalterapeut word ten slotte bespreek.

KEY WORDS: geodesic learning, mind mapping approach

\section{INTRODUCTION}

Humans are biologically designed to survive and the single greatest competitive advantage is the ability to learn (Jensen, 1995: iv).

\section{TRADITIONAL PERCEPTIONS OF LEARNING}

The ability to learn, individually, in groups, in organisations and as a country, is a critical factor in the progress and development of society as a whole. Traditionally, definitions of learning have been based on behaviouristic, mechanistic and cognitive theories (Glasser, 1986; Knowles, 1990). This has led to the assumption that learning is the internalisation of external knowledge, and is under the control of a single internal source of self-regulation, namely executive self-regulation (Iran-Nejad, 1990). This viewpoint defines learning as a growth process dependent on internalising events into a "storage"

system that corresponds to the environment (Knowles, 1990). Therefore, most traditional learning theorists view learning as a process by which behaviour is changed, shaped or controlled, with an emphasis on growth and cognitive development (Knowles, 1990; Glasser, 1986). However, these assumptions undermine the creative and multimodal nature of learning, limiting learning to the simple incremental learning of facts and definitions, which in turn is responsible for the achievement and motivational problems many students experience (Glasser, 1986; Iran-Nejad, 1990; Gardner, 1985; Knowles, 1990; Jensen, 1995). It appears that behaviouristic and cognitive theories are too narrow to explain the complexity of the learning process as their primary focus is on concept attainment to the exclusion of concept formation or invention (Glasser, 1986; Jones, 1968, in Knowles, 1990). Furthermore, it needs to be acknowledged that that everyone learns in different ways, and that it is consequently necessary to explore alternative 
ways of facilitating learning that will allow individuals to realise their natural potential. Current traditional learning systems that propose to stimulate learning in the "whole" child, tend to favour predominantly linguistic and mathematical intelligences as opposed to a more pluralistic approach (Jensen, 1995). This is a consequence of the prevailing philosophy of current traditional educational systems and therapeutic institutions which indicates that "intelligence" or "potential" is a single general capacity that enables the individual to achieve in all situations. Research has, however, indicated that the traditional type of approach to developing learning potential, which is based on the I.Q., Piagetian and Information Processing movements, is product versus process oriented and does not develop the whole person in their full capacity (IranNejad, 1990; Gardner, 1985; Jensen, 1995). Many educators and philosophers concur that the most important goal of therapy and education is to facilitate thinking. Hence an approach to learning is needed that moves away from viewing learning as a process of controlling, changing or shaping behaviour, to one that views learning as competency development. Consequently, an alternative approach that focuses on the dynamics of the thought processes and the pluralistic nature of the intelligences of the human mind has arisen, and which is termed the geodesic movement (Leaf, 1997; Gardner, 1985; Iran-Nejad, 1990).

\section{THE PARADIGM SHIFT IN SPEECH-LANGUAGE THERAPY AND AUDIOLOGY}

The paradigm shift that is occurring in the perception of learning is parallelled in the field of Speech-Language Therapy and Audiology, and has resulted in a paradigm shift in the professional self-concept and role played by the speech-language therapist. This paradigm shift has emerged in response to the increasing awareness of the inefficiency of traditional approaches in meeting needs of clients, with alternative service delivery models proposed to provide a more accountable service to clients (PaulBrown, 1992; Simon, 1987; Leaf, Uys \& Louw, 1990; Lewis 1994). One of the communication needs stressed in the alternative service delivery literature is the need to integrate communication skills with academic material with the emphasis on the learning process (Paul-Brown, 1992). This is due to the academic environment requiring competent communication skills - both oral and written as prerequisites for school success (Johnson, 1987). A student's successes and failures are bound up in the way they share and create meaning through language. Speech-language therapists therefore need to broaden their role to promote overall learning success, and in this way, provide a more accountable service to clients. Speech-language therapists need to become more involved in facilitating the language and communication skills needed in the learning process in the classroom. This change therefore implies an evolution. According to Johnson (1987:225), "the evolution from "speech-language therapist" to "communication and learning instructor" has been the result of adopting an educational versus a medical model, through integrating communication instruction into the students natural learning environment, and through collaborating with other educators". This entails the use of classroom and curriculum based service delivery models where the basis for the content of treatment would be the concepts and vocabulary from the academic curriculum. This implies a consultative role for the speech-language therapists allowing for their background and abilities to be utilised to a greater extent. Not only can speech-language therapists provide direct therapy, but they can also provide input on the communication and social difficulties exhibited by the pupils as observed in the naturalistic learning environments, as well as about the process of language and learning in general (Thurman \& Widerstrom, 1990).

\section{HUMANISM VERSUS BEHAVIOURISM}

The development of Humanistic Psychology (founded in 1963) carries this trend of thought further in that the image of man is recast from a passive, reactive recipient to an active, seeking, autonomous and reflective being (Rogers, 1969, in Knowles, 1990). According to Rogers (1969, in Knowles), learning is seen as having a quality of personal involvement; as being self-initiated; as pervasive; as evaluated by the learner; and finally, as having meaning as its essence. This view is expanded by Maslow (1970, in Knowles, 1990) who identifies the goal of learning to be self-actualisation. Jourard argues that "the learner has the need and the capacity to assume responsibility for his own continuing learning" (1972, in Knowles, 1990). This humanistic view of learning has been formulated into a theory by Glasser (1986) which he calls "learning control theory". Learning control theory is a biological theory of how humans function as living creatures. It has as its basic premise the contention that all behaviour is an attempt to satisfy needs that are built into the genetic structure of the brain, and thus all motivation is internal, as opposed to external - as claimed by behaviourists and cognitists. Control theory contends that it is impossible to force or bribe a person into doing quality work. That is, learning is not a process of shaping change in behaviour, rather it is an internally motivated creation of meaning (Glasser, 1986). Iran-Nejad (1990) elaborates on this idea by defining learning as the creative reconceptualisation of internal knowledge. He further proposes that there are two different sources of internal self-regulation; one that controls the sequential conscious aspect of learning, 'and another that controls the simultaneous non-conscious aspect. Furthermore, to extend the domain of learning beyond simple incremental memorisation, both sources of self-regulation have to be activated.

Both the behaviouristic and cognitive theories, which utilise computers and mechanistic processes as analogies, define learning as a change in behaviour that is largely controlled by an external source, and that will result in an accrual of knowledge facts. By contrast, humanistic theories, which have the functioning of the human brain as their analogy, define learning as an internally motivated and controlled process that results in the recreation of conceptual knowledge with the emphasis on meaning. Behaviouristic and cognitive theories emphasise the educator, the agent of change who presents stimuli, and reinforcement for learning and designs activities to induce change. A humanistic approach, by contrast, emphasises the person in whom the change occurs, and learning as the act or process by which behavioural change, knowledge skills and attitude are reconceptualised. In this, a humanistic approach to learning appears to be a more accurate description of human functioning than a behav. 
iouristic and cognitive approach. Extensive research has been conducted in the fields of contemporary neuroscience and neuropsychology and has led to the identification of the brain's preferred way to learn, confirming the latter statement (Glasser, 1986; Gardner, 1985; Iran-Nejad, 1990; Jensen, 1995; Knowles, 1990; 1986; Lozanov, 1978; Dhority, 1991; Springer \& Deutsch, 1989; Diamond, 1988). However, behaviouristic and cognitive theories tend to dominate the philosophy of learning institutions with what are believed to be negative effects on the learning abilities of students and clients and the realisation of their potential. The adoption of predominantly behaviouristic and cognitive philosophies is possibly due to a lack of integration between research on the brain and standard education practices.

In addition, the behaviouristic and cognitive theories provide neat ways of "measuring" and "packaging" students and clients into controlled environments, and are thus convenient to educationalists and learning institutions. The humanistic approach recognises the complexity and individuality of human nature, and consequently the complex and involved task of facilitating learning. This approach is not as convenient or controllable.

Cremin (1981, in Knowles, 1990) indicates that the revolution in learning that began in the twentieth century and is continuing into the twenty-first century may be as fundamental as the original invention of formalised learning institutions. A strong case for the adoption of alternative approaches to learning is made by Capra (1982, in Knowles, 1990). He argues that "we are trying to apply the concepts of an outdated world view - the mechanistic world view of Cartesian-Newtonian science - to a reality that can no longer be understood in these terms. We live in a globally interconnected world, in which biological, psychological, and environmental phenomena are all interdependent. To describe this world appropriately, an ecological perspective is needed that the Cartesian world view cannot offer" (Capra, 1982, in Knowles, 1990: 19). Capra further argues that a fundamental change is needed in thoughts, perceptions and values, and thus, attitudes. The beginnings of this change are visible in most areas and are likely to result "in a transformation of unprecedented dimensions, a turning point for our planet as a whole" (Capra, 1982, in Knowles: 19).

Thus, a paradigm shift is needed in order to create new learning systems that focus on the development of potential which is achieved through teaching how to learn and not what to learn. There are many reasons for a paradigm shift in learning, not the least of which is that in the USA more than $40 \%$ of school-going children are diagnosed as having some kind of learning problem (Jensen, 1995; Thornburg, 1991, in Jensen, 1995; Simon, 1987). However, it is felt that this percentage is in fact higher, closer to $90 \%$ than $40 \%$, and that the reason for this high percentage is the system within which pupils are being "educated". The current educational system is producing "educational casualties" (Simon, 1987), rather than innovative lifelong learners. This constitutes a major problem because learning is an ongoing process that crosses all walks of life, and the application of traditional behaviouristic and cognitive learning systems is not preparing children for life (Knowles, 1990). According to Mitchell (1986, in Buzan \& Dixon, 1976), society needs a more extended view of what normal human potential is, implying that high achievers are the norm and not the excep- tion. This involves a totally new and broader approach to the perception of learning, and, therefore, of educating and remediating.

In summary, it appears that traditional approaches to education and therapy are based on the I.Q., Piagetian and classical information processing theories of learning. These approaches all focus on a certain kind of logical or linguistic problem-solving; ignore neurobiology; do not deal with higher levels of creativity; and finally do not consider the ethnography of learning. The result of such approaches is less than optimal as, according to research, 70- 90\% of students are underachieving, many of whom require additional support in the form of therapy (Iran-Nejad, 1990; Bloom, 1984). Bloom (1984, in Iran-Nejad, 1990) states that for more than thirty years students have been memorising facts and definitions without understanding them. Sizer (1984:84) indicates that "students are all too often docile, compliant and without initiative, painting a picture of considerable passivity towards academic learning and school". A non-intelligent learning culture of not thinking has thus resulted, producing students who do not take responsibility for their learning, and who are reliant on external sources to do their thinking for them.

\section{THE GEODESIC MOVEMENT}

The geodesic movement by contrast, focuses on the symbolic vehicles of thought, namely the activities and products of the human mind such as language, mathematics, visual arts and gestures (Gardner, 1985; IranNejad, 1990: Allport, 1980; Hinton \& Anderson, 1981). The geodesic movement moves away from the search for general problem-solving devices and horizontal structures such as memory, attention and perception, and focuses more on vertical components, hence providing a more molar and molecular analysis of the nervous system (Allport, 1980). This approach is not entirely new, as facets of the mind were already recognised in ancient Greek philosophy, and it can thus be seen as a type of rejuvenated faculty psychology. The geodesic movement does not merely focus on the linguistic, logical and numerical symbols of Piagetian, I.Q., and information processing theories, but also focuses on a full range of symbol systems encompassing musical, bodily, spatial and personal symbol systems, and is consequently multimodal (Gardner, 1985: Leaf, 1997). Each symbol system can be viewed as an independent functioning cluster of intelligences making up that particular symbolic domain, and, although separate, the domains do interact in the thinking process (Gardner, 1985). The geodesic is biologically oriented and is based on brain organisation and maturational capacity. Thinking is perceived to consist of a number of special purpose devices, or clusters of abilities presumably dependent on neural "hard-wiring" in the brain (Allport, 1980). Furthermore, cognitive accomplishments may occur in a range of domains some of which are universal, such as the logical-mathematical domain which forms the basis of experimentation in the I.Q., Piagetian and Information Processing movements (Feldman, 1980). Some are culturally specific such as reading which is important in some cultures and not in others. Within each domain there are steps ranging from novice to expert, making the movement developmental. However, there are great inter-individual differences in the speed at which an individual passes through the stages from novice to mas- 
tery in the different domains. In contrast to Piaget's theory, success at negotiating one domain does not invoke the other domains (Feldman, 1980). The development of domains is dependent on internal genetic factors as well as on external cultural factors (Gardner, 1985).

Therefore the geodesic movement represents a shift from cognitive theories of knowledge to cognitive theories of how the nervous system functions. (Iran-Nejad, 1990; Hinton \& Anderson, 1981). This development suggests that simultaneous learning in diverse local sites and subsystems of the nervous systems is the rule for learning, as opposed to one-thing-at-a-time rule of traditional approaches. According to Iran-Nejad (1990), if previously unrelated local sites in the brain, representing domains, are stimulated simultaneously in a brain-compatible way, they will combine in configurations previously not experienced and result in higher levels of functioning. This simultaneous learning hypothesis, which is central to the geodesic movement, suggests that more than active conscious control is needed to think, learn and release potential. It implies that another kind of control must be operating on the non-conscious level, and both types of control are needed in effective learning. This control is called dynamic self-regulation, and is simultaneous, implying that simultaneous functioning is a prerequisite for learning as opposed to the other way around as in traditional approaches. Furthermore, dynamic self-regulation operates on the non-conscious level, yet will impact the conscious level through a process of attention delegation, which is the power to contribute to the learning process even though not conscious (Iran-Nejad, 1990).

This simultaneous, non-conscious process permits individuals to engage in multimodal encoding, unencumbered by potential interference from one-modality-at-atime executive encoding which is characteristic of many learners exposed to traditional approaches, and results in a cautious literal attitude to learning. Learning in the traditional mode becomes increasingly analytical, intentional and potentially very sequential because the learner is using the rehearsal-memorisation strategy of allocating immediate attention to every physical item of the task over and over again, without regard for the powerful contributions of spontaneous, tacit and explicit attention-delegation processes of dynamic internal self-regulation. The geodesic approach represents a way of creating a more thinking-orientated approach to learning. A fundamental tenet underlying geodesic learning is that a mediator cannot cause learning in an individual, learning must be created by the learner. Thus the mediator should structure the environment to facilitate the learning process (Feuerstein, 1980).

Within the alternative geodesic approach, with the altered perception of learning, is the implication of an expanded role for the speech-language therapist working in educational settings. Traditionally the speech-language therapist has employed a clinical model of intervention focusing on the oral linguistic aspects of language - (Simon, 1987; Paul-Brown, 1992). This latter approach has led to a focus on deficits and remediating deficits - a symptomatic approach. For example, viewing syntax, semantics, pragmatics and auditory processing as separate variables while ignoring the reading and writing aspects of communication leads to fragmented services that drill splinter skills (Simon, 1987; Paul-Brown, 1992). In the field of education, specifically Simon (1987) postu- lates that well-meaning traditional speech-language approaches have actually ended up creating "educational casualties" as a consequence of segregating and labelling students, leading them to become addicted to $1: 1$ attention. This has led to the development of passive attitudes towards learning by falling into patterns of "learned helplessness" due to believing their "disabled" labels (Johnson, 1987). Alternative service delivery approaches have consequently emerged in response to the increasing awareness of the inefficiency of traditional approaches to communication, with immediate impact on the role of the speech-language therapist.

Thus, the most significant implication arising out of the literature related to the development of lifelong innovative learners with proficient communication skills, concerns the need to move from teaching and facilitating specific skills to the teaching of strategies to enable students to attain mature language repertoires and communication competence with adequate problem-solving skills (Thornburg, 1991, in Jensen, 1995; Derry, 1990). The speech-language therapist, with a background in language, communication, psychology, speech and hearing science, linguistics, and learning theory, is eminently qualified to become involved in the integration of a geodesic approach to the process of learning and intellectual development, which indicates the expanded role for the speech-language therapist working with learning problems (Paul-Brown, 1992). As discussed, speech-language therapists should view themselves as language specialists concerned with the prevention and remediation of communication difficulties by focusing on the process of learning and intellectual development (Thornburg, 1991, in Jensen, 1995). The speech-language therapist is seen to play an important role academically in assisting with adapting the child's academic instruction so that he can achieve to the best of his ability (Committee on Language, Speech and Hearing Services in Schools, 1983, in Johnson, 1987). This implies that a complex relationship exists between language used for learning and intellectual development and language used for communication, highlighting the need for a paradigm shift in the perception of learning. In view of the foregoing, research highlighting and emphasising the necessity of a learning paradigm change is needed if educational institutions are to facilitate the development of innovative lifelong learners that can make a contribution to society.

The overall objective of the research on the geodesic information processing model, and its application, the Mind-Mapping Approach (MMA) (Leaf, .1990; 1997), is therefore to create and explore an alternative system to the traditional learning system. The Mind-Mapping Approach (MMA), is believed to provide a better way to assist learners - teachers, therapists, pupils and clients alike - in becoming innovative lifelong learners. This is because the theoretical base of the MMA incorporates the principles inherent in the philosophy of geodesic learning, which is the suggested alternative philosophy upon which the perception of learning should be based, and which falls within the realms of a humanistic approach. The MMA framework provides a basis for bridging the gap between the unique individual learner and the design and delivery of the learning experience. The latter is in contrast to traditional educational and institutional systems of facilitating learning and communication, which are based on unnatural behaviouristic, mechanistic and cog- 
nitive philosophies which undermine the complexity and hence the potential of human nature.

In view of the complex nature of learning, intellectual potential and communication, approaches of a more geodesic nature need to be adopted by educationalists and speech-language therapists in learning institutions in order to increase the efficacy of service delivery (Simon, 1987). This implies a paradigm shift from traditional behaviouristic and cognitive approaches to geodesic approaches to learning and communication (Gardner, 1985; Dhority, 1991; Jensen, 1995). This paradigm shift can be facilitated by practical frameworks incorporating geodesic principles. The MMA is viewed as a framework of this nature.

This theoretical model also serves as a foundation for the expansion of the concept of the Mind-Map (Leaf, 1990; Leaf, Uys \& Louw, 1993). The expanded view of MindMapping views the Mind-Map as the key which accesses the non-conscious levels of the brain. The Mind-Map is seen to directly access and influence the thought processes serving to unlock the potential of the brain. Hence the Mind-Map will be shown to be the creative symbolic visualisation of the raw material of consciousness, that is, the synchronised electrical-chemical reactions of the neurons.

It is the purpose of this paper to explain the development of the theoretical model, the geodesic information processing model in terms of its operation and theoretical assumptions. The importance of a theoretical base in the development and application of an alternative approach to facilitating a creative learning process in students and clients is stressed. The concepts inherent in the geodesic information processing model are general geodesic principles and can therefore be extrapolated and used in therapy and education. The MMA and the expanded conception of the Mind-Map do, however, provide a framework that incorporates all geodesic principles in a practical way, and will be discussed in ensuing papers.

\section{EXPLANATION OF THE GEODESIC INFORMA- TION PROCESSING MODEL}

In this section, the components of the geodesic information processing model and their operation will be described.

\section{ORIENTATION}

The geodesic information processing model was developed to explain the thinking process invoked by using the geodesic techniques of the MMA. The emphasis of the MMA is to capitalise on the natural multimodal functioning of the brain in order to reconceptualise useful knowledge and develop potential.

The four components of a geodesic approach, namely metacognition, cognition, neuropsychology and symbolism, are incorporated into the geodesic model. The theoretical underpinnings of the development of the model have been derived from contemporary brain research: the work of Iran-Nejad (1990) on the two-source theory of self-regulation; Lozanov's $(1975,1978)$ development of Suggestopeadia; Gardner's $(1980,1985)$ research on symbolic systems and the multiple intelligence theory; contemporary metacognitive and cognitive research, specifically on the role of the non-conscious (Flavell, 1978); and finally symbolic system ${ }^{i}$ approaches to information pro- cessing which use the brain as the analogy for the mind (Hinton \& Anderson, 1981).

The geodesic information processing model is presented in schematic form in Figure 1. This is accompanied by a gestalt overview of its operation followed by an in-depth explanation and discussion of its components and their operation.

\section{AN OVERVIEW OF THE OPERATION OF THE GEO DESIC INFORMATION PROCESSING MODEL}

The geodesic information processing model (Figure 1) is a hypothetical model that traces the information processing pathway from the input - which can be internal, external or both - to the output whilst using a geodesic framework such as the MMA. It is, however, postulated that this model can be extrapolated to explain any approach that strives to facilitate the processing of information within an environment that follows the natural laws of functioning of the brain.

As the result of an internal or external input, or both, information begins to be processed (see figure 1). If the geodesic framework, the MMA is utilised, specific metacognitive module(s) will be activated by a patternmatching process. This will result in the activation of the processing systems of the specific metacognitive module(s) to be involved in the task.

In order for the processing system to operate, metacognitive action (see Figure 1), needs to be instituted, that is, the interaction of declarative, procedural and conditional knowledge executed by dynamic self-regulation. This will lead to the selection of the function to be carried out, facilitated by the activation of existing descriptive systems to assist in the reconceptualisation of the new knowledge, and the cognitive process will begin. At this point, active and dynamic self-regulation interact. The quality of this interaction is controlled by the geodesic nature of the MMA.

The cognitive domain (see Figure 1), has to match the processing system already selected, and therefore the cognitive requirements of content, form and use will need to be met before quality processing can continue. If the cognitive requirements are fulfilled, then the cognitive function(s) will be selected to carry out the cognitive task to completion. In order to operationalise the cognitive function(s), cognitive action begins. Finally, the result of the information processing will be expressed through a symbolic format which is known as the output. The evidence of the newly reconceptualised knowledge is visually available on the Mind-Map, and represents the overt evidence that thought has taken place.

The geodesic information processing model (Figure 1) is divided into four components, namely the metacognitive, cognitive, symbolic and neuropsychological components. The operation and interaction of each of these components is now discussed.

\section{THE METACOGNITIVE COMPONENT}

\section{Description}

The metacognitive component comprises seven metacognitive modules (see figure 1), each of which can be broken down into processing systems. Each processing system is made up of functions that realise the potential 


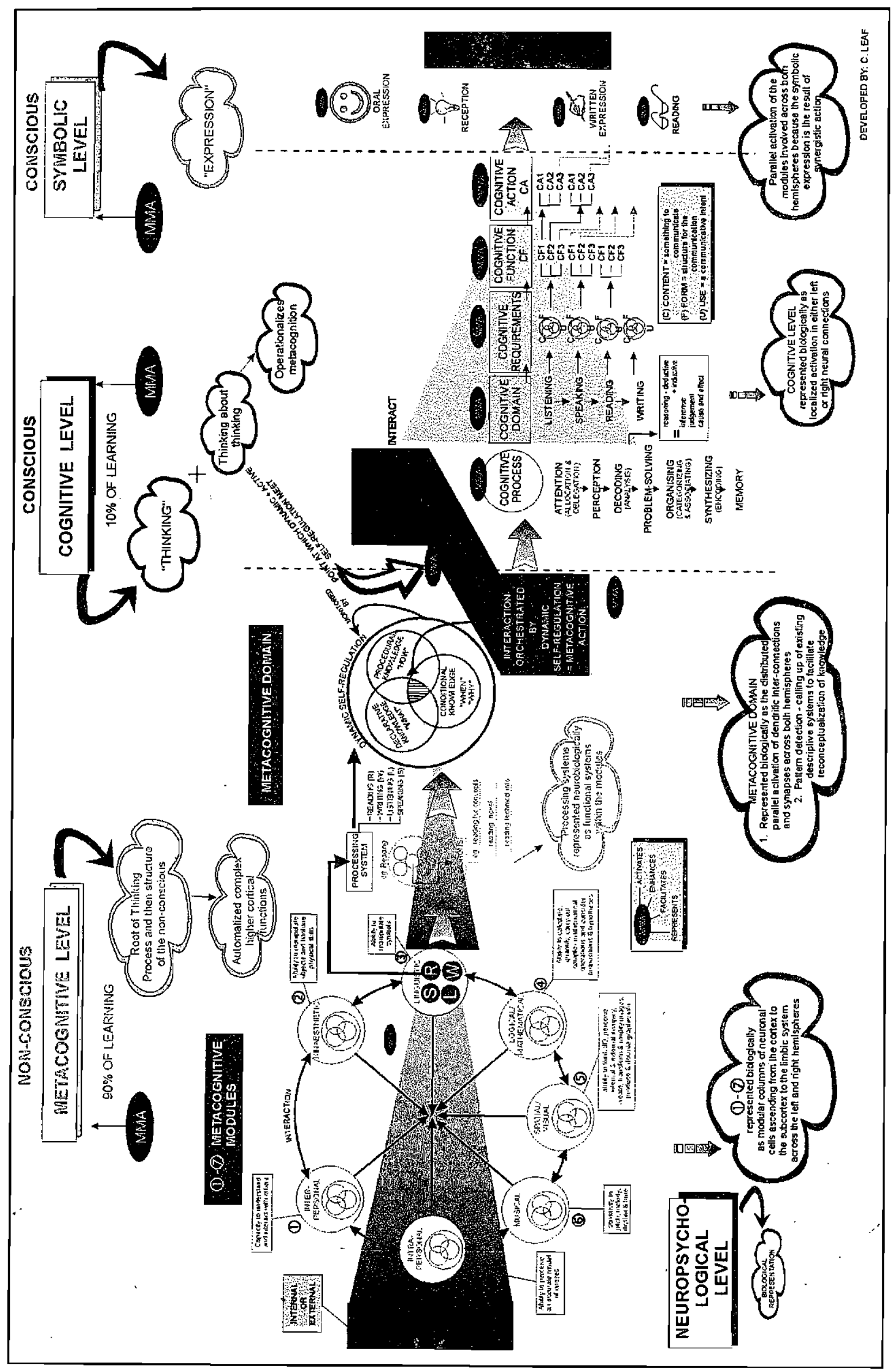

过

The South African Journal of Communication Disorders, Vol. 44, 1997 
of that processing system. This realisation of the potential of a processing system is made possible by its computational capacity, the activation of the metacognitive domain.

\section{The seven metacognitive modules}

The metacognitive modules represent the knowledge base of the mind, categorised into seven groups based on the multiple intelligence theory (Gardner, 1981, 1985). These seven are not exhaustive but are seen to be representative of the range of human knowledge and intellectual potentials (Gardner, 1985; Kline, 1990).

The seven modules are the linguistic, logical /mathematical, visual/spatial, musical, inter- and intrapersonal, and kinaesthetic domains of knowledge. According to Gardner (1985), owing to heredity, early training or both, some individuals will experience greater development within some domains of knowledge than others, but every normal individual should develop each domain to some extent.

In life, these domains of knowledge (called metacognitive modules in the current model because of the metacognitive and information processing perspective) work in harmony, and so their autonomy may be invisible. However, Gazzaniga (1977, in Gardner, 1985) argues that they function as independent units each with their own cognitive characteristics. It is therefore proposed that the integrative cognitive nature of the MMA facilitates the interaction of these modules. When these modules interact, higher order thinking is produced because the net result of the interaction between modules improves the quality of interaction within modules. Strength in the sum of the parts is the fundamental principle of this modular perspective. The quality of higher cortical functions is influenced by the harmonious interaction of modules which is facilitated by creating environments that tap the abilities of all the modules, as opposed to just one or two, as is the case with traditional approaches. Synchronised interaction is facilitated within multimodal frameworks such as the MMA.

It should be noted that in Figure 1 (the geodesic information processing model), the expansion from the metacognitive level to the cognitive level, to the symbolic level is shown only in the linguistic metacognitive module. However, it is proposed that each metacognitive module follows this selfsame expansion within its domain of

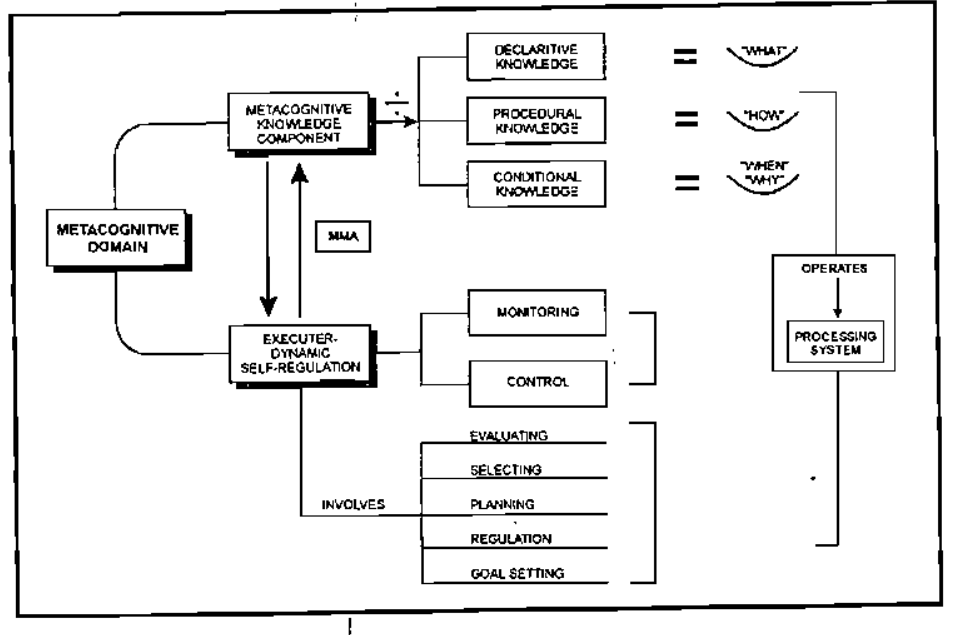

FIGURE 2: The Metacognitive Domain knowledge.

\section{The processing systems and their functions}

A metacognitive module is further subdivided into processing systems which (see figure 1) are the result of a whole system of functions. These are represented neurologically by interrelations of different parts of the brain, based on Luria's (1980) conception of functional systems.

Each metacognitive module has its own specific processing systems, which are represented across both hemispheres in the brain. The processing systems are made up of functions which are locally represented in specific areas of either the left or right hemisphere of the brain. For example, the linguistic metacognitive module has various different processing systems such as reading, writing, communicating and listening. Each of these, in turn, can be divided into their functions. Thus, for the processing system of reading, the function could be reading to find the key concept, or reading a complex technical manual, or reading a novel for pleasure. Each of these functions requires different cognitive approaches and is made up of various different steps - termed cognitive actions - which will operationalise the cognitive task.

\section{The metacognitive domain - the computational capacity}

A computational capacity exists at the core of each metacognitive module which is unique to that particular metacognitive module, and on which its complex realisations are based. From the repeated use of, interaction among, and elaboration of the various computational devices, forms of knowledge will eventually flow that could be termed useful, thus contributing to intelligence. These forms of knowledge have the potential to be involved in symbol systems, and will ultimately be expressed on the symbolic level.

More specifically, these computational capacities, which are unique to each of the metacognitive modules, are termed the metacognitive domains. A metacognitive domain comprises declarative, procedural and conditional knowledge with its executor being dynamic self-regulation. Each processing system operates under the direction of the metacognitive domain for that particular metacognitive module. Figure 2 illustrates this relationship schematically.

An example of the interplay in the metacognitive domain

A hypothetical example of the dynamic interplay between the declarative, procedural and conditional knowledge components, and their executor - dynamic self-regulation as invoked by the MMA - would involve the following. Initially an externally- or self-imposed goal is established (the equivalent of internal or external input). The existing metacognitive knowledge concerning this particular objective leads to the conscious metacognitive experience (interaction between active and dynamic self-regulation) that the objective may be difficult to achieve. This metacognitive self-regulation, combined with additional metacognitive knowledge, results in the selection and use of the cognitive strategy (termed cognitive act on the schema) of asking ques-

Die Suid-Afrikaanse Tydskrif vir Kommunikasieafuykings, Vol. 44, 1997 
tions of oneself or knowledgeable other people. The answers arising from this exercise stimulate additional metacognitive experiences about the success of the task, which represents the interaction between active and dynamic self-regulation. These experiences, guided by relevant metacognitive knowledge (declarative, procedural and conditional), investigate the cognitive strategy (cognitive act) of surveying, to establish whether it forms a coherent whole which provides a solution to the problem. This overview may result in the identification of difficulties with consequent activation by metacognitive knowledge and experience (active and dynamic self-regulation) of the same or different cognitive strategies. This interplay continues until the symbolic representation is achieved, which is the final creation of the Mind-Map.

\section{The activation of the metacognitive module - metacognitive action}

In order to activate a metacognitive module, the components of the metacognitive domain (declarative, procedural and conditional knowledge) need to interact. This interaction results in metacognitive action, and is orchestrated by dynamic self-regulation. The quality of the interaction of the metacognitive domain determines the eventual output.

In the creation of the Mind-Map, all three types of knowledge need to be considered when selecting the concepts, as well as when representing these in an associated way. The process of creating the Mind-Map enhances the interaction of declarative, procedural and conditional knowledge, resulting in metacognitive action.

When metacognitive action occurs, the process of cognition begins. As mentioned earlier, 90 per cent of learning takes place on the non-conscious level (Gardner, 1985; Iran-Nejad, 1990). The rationale for this is that "intelligent" learning is creative and multisource, and hence takes place on the non-conscious level (Iran-Nejad, 1990).

Traditional approaches assume that learning occurs under active conscious executive control, namely from a single source termed metacognition (Iran-Nejad, 1990; Dhority, 1991). As a result effortful attention (Iran-Nejad, 1990 ) is viewed as the single most important regulator of learning (Bereiter, 1985). This limits the domain of learning. In the current study, based on a literature review on the non-conscious and self-regulation, metacognition is redefined as occurring on the non-conscious level (IranNejad, 1990; Dhority, 1991; Lozanov, 1978; Flavell, 1978). These authors postulate the notion that external and internal stimuli are far too complex to manage or hold with only the mechanisms of our conscious attention. Hence the non-conscious level is not viewed as simply containing the unattended or unimportant percepts, but as the level where the complex mental activity occurs. A structure for the non-conscious level is postulated, thus providing a broader definition of metacognition. By implication, 90 per cent of learning is taking place when metacognitive action is in process, and hence this is the level that should be targeted in intervention and mediation.

The activation of the non-conscious stores triggers metacognitive action. The MMA can be seen as this trigger. By implication, the MMA focuses at the root level of the learning process, and therefore predominantly on the non-conscious. Conversely, the cognitive functions that have been activated by metacognitive action, and that are orchestrated by active and dynamic self-regulation, only represent approximately 10 per cent of the learning and reconceptualisation of knowledge process (Reddy, 1979, in Iran-Nejad, 1990; Lozanov, 1975).

\section{The neurobiological level of metacognitive action}

On a biological level, modular columns of neuronal cells ascending from the cortex to the subcortex to the limbic system across the left and right hemispheres, represent the metacognitive modules and functional systems (See figure 1) (Feldman, 1980). Metacognitive action is represented as the distributed parallel activation of dendritic interconnections from the cortex to the limbic system across both hemispheres.

\section{The neuropsychological level of metacognitive action - pattern recognition}

On a neuropsychological level, metacognitive action can be perceived as the activation of the descriptive systems (Goldberg \& Costa, 1981), or organisational codes. The number of descriptive systems activated is dependent on the complexity of the cognitive task. These will be used to reconceptualise new descriptive systems based on pattern recognition. The Mind-Map's pattern structure facilitates the pattern recognition process, as well as making it available to introspection, and in this way more efficient use of the descriptive systems can be made.

\section{The interaction of active and dynamic self-regula- tion}

Active self-regulation occurs on a conscious level, which implies that conscious introspection can occur. This is the result of the interaction of dynamic and active selfregulation (see hypothetical example above). According to Iran-Nejad (1990), this interaction has important implications for learning because the quality of this interaction distinguishes between effective and ineffective approaches to learning. Therefore, active and dynamic self-regulation have to interact in order to produce cognition. Once the cognitive process is instituted, active and dynamic self-regulation should continue to interact, and the nonconscious will impact on the conscious level through attention delegation. This will lead to "quality learning". However, if active self-regulation starts to operate at the expense of dynamic self-regulation, which can occur if the facilitation is brain-antagonistic (Jensen, 1995), as in traditional approaches, then the quality of learning lessens and learning becomes more rote-like.

A single-source theory of self-regulation implies that the central executive must monitor constructive change by directly allocating attention to the source of change (Reddy, 1979, in Iran-Nejad, 1990). The two-source alternative (Iran-Nejad, 1990) implies that active allocation of attention is neither sufficient nor always necessary. An activated descriptive system (the result of metácognitive action) can influence a cognitive task, even though it may be outside conscious awareness. Therefore the activated descriptive system will still influence higher mental functions or cognitive tasks and strategies being used to complete a goal - be it of a communicative or academic nature. This is known as attention-delegation power, which is the 
power to continue an ongoing contribution to internal reconstruction even after the executive spotlight moves on to another site (Iran-Nejad, 1990).

The most direct source of interaction between active and dynamic self-regulation occurs when specific attention is allocated to the components (Iran-Nejad, 1990). These are the declarative, procedural and conditional knowledge components of the metacognitive domain in the information process model. It is postulated that this interaction is enhanced by the MMA due to its metacognitive nature. This process is evidenced during the act of creating a Mind-Map, where essentially declarative, procedural and conditional knowledge is stored. In the selection of a concept, metacognitive action sequences are established which indicate the associative relationships in a deductive and inductive way, therefore analogically. Thinking on this level is considered to be deep processing as the metacognitive level is actively involved.

If the incorrect concept is selected due to lack of comprehension or the attempt to learn in a rote fashion, incorrect action sequences will be stored, which will affect recall. This is easily rectified by reviewing the networked patterned nature of the Mind-Map. In this way the metacognitive components (which have become conscious by their visual symbolic expression on the Mind-Map, and therefore regulated by active self-regulation) will be activated.

However, the metacognitive action sequences are governed by the non-conscious level (Anderson, 1986, in Springer \& Deutsch, 1989), and therefore dynamic selfregulation, and will be activated on a non-conscious level. Hence, in order to rectify the incorrect action sequences, active and dynamic self-regulation have to meet and interact. It is this interaction that becomes a primary focus of the MMA because, as already stipulated, the quality of interaction will distinguish between effective and ineffective approaches to learning. It is hypothesised that the MMA improves the quality of the interaction because it accesses the cognitive and metacognitive levels in its construction. Figur' 3 illustrates the relationship between active and dynamic self-regulation and metacognition and cognition. Therefore, the metacognitive nonconscious is the highest level of thought, where qualitative, intelligent and useful knowledge is reconceptualised. Traditional forms of stimulation will result in only partial activation of this level, and hence the lack of activation of potential.

\section{THE COGNITIVE COMPONENT}

\section{Description}

The cognitive component of the geodesic information processing model represents what is traditionally assumed to be metacognition, that is, "thinking about thinking" (Flavell, 1978). In the model (see figure 1), this level represents the level on which slow, conscious control of the thought process occurs. It is under the control of the central executive and is inherently sequential. The cognitive process begins after metacognitive action is instituted, when dynamic and active self-regulation interact.

\section{The cognitive process}

When metacognitive action is instituted, cognition (see figure 1), orchestrated by active and dynamic self-regulation, begins, the interaction between the two being of paramount importance. On the cognitive level, the metacognitive action is carried out to completion. This completive action is constantly enhanced by the use of the MMA framework. In order to complete the metacognitive action, the cognitive process will be instituted on the product of the metacognitive action. This is the process that is instituted as the Mind-Map is being made. These action sequence steps include the following:

- Attention allocation and delegation;

- Perception through all the sensory modalities;

- The decoding (analysis) of the incoming information (this involves the analysis of existing appropriate descriptive systems already called up when metacognitive action began) in preparation of the new reconceptualisation of knowledge;

The process of problem-solving, which includes reasoning, both deductive and inductive, resulting in inferences and judgements being made, and cause-effect relationships being established;

$\square$ The organisation of the resultant reconceptualisations into appropriately associated and categorised networks; and finally

$\square$ The synthesising (encoding) of information that will be effectively stored in memory

(Flavell, 1978; Gardner, 1985; Iran-Nejad, 1990; Jensen, 1995; Dhority, 1991; Hart, 1983; Hand, 1986).

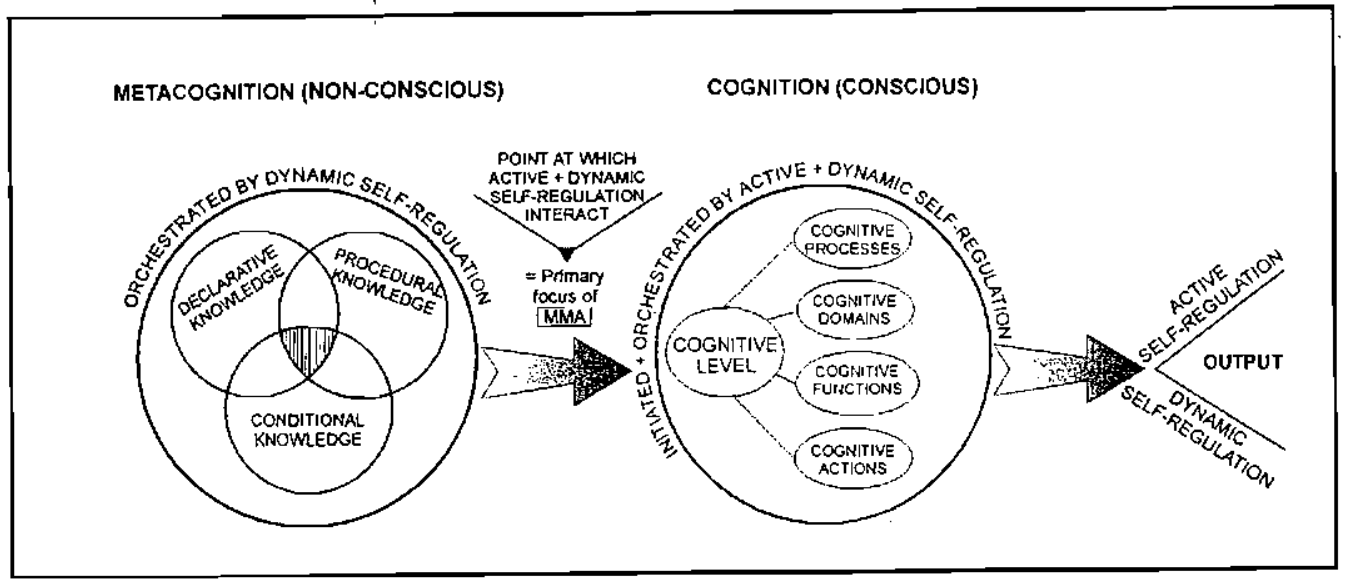

FIGURE 3: The Interaction between Active and Dynamic Self-Regulation
These cognitive processes occur within each of the cognitive domains which delineate the processing systems already activated on the metacognitive level, namely listening, speaking, reading and writing, in the case of the linguistic module. Each cognitive domain has various requirements that have to be fulfilled in order to create useful knowledge. These requirements (Bloom \& Lahey, 1978, in Leaf, 1997) include: some- 
thing to communicate (content); a structure for the communication (form); and, finally, a communicative intent (use).

The next phase of the MMA information processing model proposes that the cognitive process operates within each cognitive domain selected for the specific task at hand, if the cognitive requirements of useful knowledge have been fulfilled. Each cognitive domain is divided into cognitive functions, corresponding to the functions on the metacognitive level, which are further subdivided into cognitive actions. In this way the cognitive act operationalises the cognitive task.

\section{An example of cognition in action}

In selecting the cognitive domain (see figure 1) (processing system) of writing, the cognitive function may be to write down a selected concept onto the Mind-Map. This is CF1 (cognitive function 1) in Figure 1. CF1 would then be made up of various cognitive acts (CA1, CA2 etc) which are the steps involved in carrying out CF1.

Thus, CA1 in this case would be the analysis of the phonemes that would afterwards have to be written. This involves the posterior parts of the left temporal zone (Luria, 1978). CA2 would involve the motoric expression of the lingual sound (Luria, 1980) in order to make the contents of the sound clear. This involves the inferior portion of the left post-central gyrus (Luria, in Leaf, 1990). CA3 is the transferring of phonemes into letters involving the spatial arrangement of the graphemes, which involves the parietal-occipital part of the cortex (Luria, 1980). CA4 involves the sequencing of phonemes and graphemes while writing, which involves the pre-motor zone (Luria, 1980).

Finally, CA5 will involve the positioning of the word on the Mind-Map to fit into the associative network. Thus CA5, in this case, moves onto the symbolic level - namely level three on the information processing model.

\section{THE SYMBOLIC COMPONENT}

The symbolic component comprises the expressive level of the cognitive action, which is in turn influenced by the metacognitive component. Functioning on the symbolic level is therefore the evidence that thinking and processing of information has occurred. This is expressed through a symbolic vehicle that is representative of the metacognitive module. For example, the linguistic metacognitive module can be expressed symbolically as oral expression, reception, written expression or reading, or all of these (see Figure 2.1). The Mind-Map facilitates and represents all four forms of expression. From the symbolic level, judgements of a person's thinking, learning, intellectual potential and communication skills are made. This implies judgements as to the effectiveness of cognitive and metacognitive skills. This occurs because metacognition influences cognition which in turn influences the symbolic output.

\section{THE NEUROPSYCHOLOGICAL COMPONENT}

The last component of the geodesic information processing model is the neuropsychological component, which deals with the relationship between brain function and behaviour (see figure 1) (Tollman, 1988, in Leaf, 1990). This component is the link between the biological and cognitive levels. In order to fall within the realms of being geodesic, the brain-function-behaviour relationship cannot be overlooked (Dhority, 1991).

According to the model, the metacognitive modules are represented biologically as modular columns of neuronal cells ascending from the cortex to the limbic system across both left and right hemispheres. It is postulated that there are seven neuronal columns representing the seven metacognitive domains, as illustrated in Figure 4. As the result of input, electrical activity will flow across the columns. The more synergistic the input, the more synchronised the flow between the two hemispheres. It is postulated that when this occurs, larger areas of the brain will be utilised more efficiently. It is believed that this synchronised synergistic flow will result in the metacognitive action being activated. Thus, the reserve capacities will be mobilised. In contrast, input from traditional approaches will result in reduced unsynchronised flow between the hemispheres resulting in only active self-regulation and effortful cognition occurring.

The metacognitive domain is represented biologically as the distributed parallel activation of dendritic interconnections and synapses within the neuronal columns of the modules across both hemispheres (Cook, 1984, in Springer \& Deutsch, 1989). Neuropsychologically, this results in pattern detection (Pribram, 1971, in Leaf,1997; Hart, 1983, in Leaf, 1997), which is the calling up of existing descriptive systems to facilitate reconceptualisation of knowledge.

The cognitive component is represented as localised activation of neural connections in either the left or right hemisphere, because the processing systems at this stage are more specific (Springer \& Deutsch, 1989). Finally the symbolic component is represented as parallel activation of the modules involved across both hemispheres because the symbolic expression is the result of syner-
FIGURE 4: A Schematic Representation of the Neurobiological Arrangements of the Metacognitive Modules 
gistic action.

Therefore the geodesic information processing model provides speculation as to the type of thinking that is induced when working within a geodesic framework. It traces the processing of information from the metacognitive level through to the symbolic output. There are various assumptions upon which this model is based. An examination of these assumptions and their theoretical underpinnings is of relevance, as they lead to a redefinition of the non-conscious level, metacognition, cognition and learning. These redefinitions are pivotal in the explanation of the effectiveness of a geodesic approach to intervention and education. In the ensuing discussion, an overview of the eight assumptions of the model is presented. This is followed by a more detailed explanation.

\section{THE EIGHT ASSUMPTIONS OF THE GEODESIC MODEL: AN OVERVIEW}

There are eight assumptions underlying the geodesic information processing model (see Figure 1 and Table 1). The first of these assumptions deals with the metacognitive component of the model. It is assumed that metacog- nition is the root of the thought process controlling the cognitive process and ultimately the symbolic output. Furthermore, the key to unlocking intellectual potential occurs when the metacognitive level is activated effectively. It is postulated that traditional approaches, which are not geodesic, do not take full advantage of the metacognitive potential of the brain, and that the full spectrum of metacognition is thus overlooked. Within a geodesic approach such as the MMA, it is assumed that the metacognitive level is more adequately activated.

The second assumption postulates that metacognition is the non-conscious level. This implies that the majority of complex higher cortical functioning and learning occurs outside conscious awareness (Reddy, 1979, in Iran-Nejad, 1990; Derry, 1990). The way that metacognition is conceptualised within the geodesic information processing model provides a structure for understanding and analysing the non-conscious level.

The third assumption deals with the concept of selfregulation and relates to the metacognitive and cognitive components of the geodesic information processing model. Traditionally, this is the conscious executive control of thought which forms part of the definition of metacognition (Costa, 1984). According to Slife, Weiss and Bell

TABLE 1: The assumptions and theoretical underpinnings of the Geodesic Info; ination Processing Model

\begin{tabular}{|c|c|c|}
\hline Level & Assumptions & Theoretical underpinnings \\
\hline \multirow[t]{2}{*}{ METACOGNITION } & $\begin{array}{l}\text { 1. Metacognition is the non-conscious level that } \\
\text { accounts for the bulk of learning } \\
\text { 2. The metacognitive structure of the non-conscious: } \\
\text { (1)Metacognitive modules } \\
\text { (2) Metacognitive processing systems } \\
\text { (3)Metacognitive domains } \\
\text { 3. The interaction of active and dynamic self-regula- } \\
\text { tion is the operating system of effective thought } \\
\text { processing. }\end{array}$ & $\begin{array}{l}\text { - Automaticity research } \\
\text { - Multi-source self-regulation } \\
\text { theory } \\
\text { - Modular theory } \\
\text { - Suggestopaedia } \\
\text { - Multiple intelligence theory. } \\
\text { - Lurian theory } \\
\text { - Metacognitive research } \\
\text { - Descriptive system theory }\end{array}$ \\
\hline & $\begin{array}{l}\text { 4. The cognitive component is the level on which con- } \\
\text { scious sequential thought occurs. } \\
\text { 5. Memory enhancement, as part of the cognitive } \\
\text { process, is contextual and content based specific to } \\
\text { each module. }\end{array}$ & $\begin{array}{l}\text { - Self-regulation theory } \\
\text { - Cognitive research } \\
\text { - Taxon and local memory } \\
\text { - Memory enhancement } \\
\text { research }\end{array}$ \\
\hline & $\begin{array}{l}\text { 6.1 Synergy between the hemisphers releases } \\
\text { potential. } \\
\text { 6.2 } \begin{array}{l}\text { Metacognitive results in the activation of } \\
\text { descriptive systems through the process of } \\
\text { pattern recognition and feedback creating } \\
\text { open systems. }\end{array} \\
\text { 6.3 } \begin{array}{l}\text { The brain is a modular system of interlinked } \\
\text { functional systems. }\end{array} \\
\text { 6.4 } \begin{array}{l}\text { The limbic system needs to be activated in } \\
\text { order to reconceptualize useful knowledge. }\end{array} \\
\text { 6.5 } \begin{array}{l}\text { The processing of information occurs in a } \\
\text { parallel simultaneous fashion on a non- } \\
\text { conscious level, and in a sequential way on a } \\
\text { conscious level. }\end{array}\end{array}$ & $\begin{array}{l}\text { - Hemisphericity research } \\
\text { - Topographic inhibition theory } \\
\text { - Descriptive systems } \\
\text { - Pattern - recognition } \\
\text { - Feedback } \\
\text { - Modularity theory } \\
\text { - Cognitive-emotive theory } \\
\text { - Suggestopaedia } \\
\text { - PDP theory } \\
\text { - Modular theory }\end{array}$ \\
\hline & $\begin{array}{l}\text { 7. The capacity to express and communicate using } \\
\text { some symbolic vehicle. }\end{array}$ & $\begin{array}{l}\text { - Symbolic system modular } \\
\text { theory }\end{array}$ \\
\hline 1 & $\begin{array}{l}\text { 8. Intelligent learning is the reconceptualization of } \\
\text { descriptive systems leading to new knowledge. }\end{array}$ & $\begin{array}{l}\text { - Self-regulation theory } \\
\text { - Suggestopaedia }\end{array}$ \\
\hline
\end{tabular}


(1985 in Iran-Nejad, 1990), self-regulation refers to the planning, monitoring and checking activities necessary to orchestrate cognition. Iran-Nejad (1990) however, argues that this type of self-regulation, termed active self-regulation, is only part of the self-regulation process, accounting for the learning of a functional knowledge base. Overreliance on this active self-regulation results in rote learners and reduces learning potential (Iran-Nejad, 1990). It is proposed that an additional form of self-regulation, termed dynamic self-regulation, is required to overcome the inherent limitations of active self-regulation (Iran-Nejad, 1990). Dynamic self-regulation is rapid, spontaneous, multimodal and co-ordinates the simultaneous as opposed to the sequential aspects of the learning process (Iran-Nejad, 1990). It is the interaction of these two types of self-regulation that will lead to more effective learning (Iran-Nejad, 1990, 1991). Within the geodesic information processing model, the interaction of the two types of self-regulation is viewed as the operating system of effective thought processing. This interaction triggers metacognitive action (see Figure 1).

The fourth assumption deals with the cognitive component, which is responsible for the conscious sequential aspect of learning. The activation of the cognitive process is reliant on its interaction with metacognition. This in turn is orchestrated by the interaction of active and dynamic self-regulation. Therefore, according to the geodesic information processing model, the conscious awareness, or the "thinking about thinking" aspect of the thought process is a more advanced level of cognition and not metacognition, as described in traditional definitions.

The fifth assumption, also dealing with the cognitive component, is that memory enhancement is part of the cognitive process. Therefore, although memory is stored on the non-conscious metacognitive level, the actual enhancing of the memory process is facilitated by various techniques that are consciously created on the cognitive level and expressed on the symbolic level.

The sixth assumption of the geodesic information processing model is concerned with the neuropsychological component (see Figure 1). Research has indicated that the most effective way of releasing the potential of the brain is through stimulating a synergistic wholistic and complementary pattern of processing between the two hemispheres (Springer \& Deutsch, 1989). This will allow the natural, wholistic pattern-discrimination ability of the brain to function. Priibram (1971, in Leaf, 1997) argues that the brain extracts meaning through wholistic multisource pattern discrimination rather than through single facts or lists. The human brain is not designed for linear unimodal thought, but operates by simultaneously going down many paths (Hart, 1983, in Leaf, 1997). Hart (1983) stresses the importance of presenting and assimilating information in larger patterns before the details. Thus, a geodesic framework will need to utilise formats of presenting and assimilating information that allow synergistic multimodal pattern discrimination to occur. The techniques of the MMA, specifically the Mind-Map, are assumed to stimulate multisource pattern discrimination that is brain-compatible (Leaf, 1990; Leaf et al., 1993).

The seventh assumption of the geodesic information processing model deals with the symbolic component (see Figure 1). The symbolic component is the expression of the metacognitive action, which is operationalised through the cognitive process. The symbolic component deals with the capacity of human beings to express and communicate meanings through using some symbolic vehicle (Allport, 1980). It is assumed that the symbolic component reflects the thought processing of the person, and is the medium through which the thought process can be manipulated.

The eighth assumption, relating to all four components of the geodesic information processing model, indicates that intelligent learning is the result of the reconceptualisation of knowledge (Iran-Nejad, 1990). The reconceptualisation of knowledge is the end result of the thought process invoked by a geodesic framework such as the MMA. This is in contrast to traditional perceptions of learning which view learning as the incremental internalisation of external knowledge (Reddy, 1979, in IranNejad, 1990; Costa, 1984). This latter definition cannot account for the complex creative process involved in intelligent learning and limits learning to the development of a factual knowledge base.

\section{IMPLICATIONS OF THE GEODESIC INFORMA- TION PROCESSING MODEL}

Arising out of the ideas presented in the current paper, are various implications for the speech-language therapist. These include the following :-

Learning is the reconceptualisation of knowledge as opposed to the internal incrementalisation of facts.

Traditional philosophy limits the domain of learning to the simplistic internalization of externally available knowledge resulting in predominantly rote-type learning of facts and definitions (Iran-Nejad, 1990).

Most of the factual information taught within traditional environments has questionable value in terms of lifeskills, and therefore lacks in quality and usefulness (Glasser, 1986). Learning is an interactive multimodal process system, not a sequential accrual system - which is only a sub-function. It is thus limiting and inhibiting to design education and therapeutic intervention around simple behaviouristic one-thing-at-a-time stimulus response. This is not congruent with biological theories of brain functioning, which indicate that the genetic structure of the brain results in behaviour being the attempt to satisfy needs, and is thus proactive, not reactive and stimulus bound (Glasser, 1986).

If the alternative perception of geodesic learning discussed in this paper is adopted, then the emphasis will move from the memorising of facts, information and formulas, which are readily available in both books and computer software, to processes and skills.

For instance, preferred activities would be writing a play, as opposed to a grammatical writing lesson; or using co-operative groups to solve problems, or to understand a process as opposed to learning photostatted notes off by heart for a test. The idea is to immerse learners in multimodal stimulation using as many varied learning opportunities as possible. The focus would then be on the process of how to learn, which is recreating knowledge, and would therefore avoid simple incrementalisation of existing facts. The reconceptualisation of knowledge would enable students and clients to develop their ability to use what is learned, not just to know what it is. A further consideration is that special'education environments dealing with children with learning difficulties are usually characterised by a passive-acceptant approach 
(Feuerstein, 1980). Familiar simple subject matter is offered at a slower pace with emphasis on reproducing material - a simple incrementalisation of facts (Feuerstein, 1980; King \& Goodman, 1990). This results in learning environments lacking any creativity, the facilitation of higher levels of thinking or the independent performance of higher level functions - the reconceptualisation of knowledge. In order to raise children with learning difficulties to higher levels of development, a passiveacceptant approach must be replaced by a proactive geodesic approach. According to this approach, the individual is an open system capable of mental and emotional modification (Feuerstein, 1980; Jensen, 1995). A proactive geodesic approach will encourage children with learning dif. ficulties to be actively involved in normal education environments and society. This requires a process of integration facilitated by the professional in the learning environment, who needs to recognise that language, learning and communication do not exist in a vacuum (PaulBrown, 1992; Marvin, 1987). Instruction to facilitate language, learning and communication skills should be presented in natural environments requiring communication (Johnson,1987). As school is normally the natural environment for most school-going children, communication skills need to be integrated with academic content. Thus, if the professional, specifically the speech-language therapist who has expertise in language and communication, works directly in the classroom where the problems occur, strategies can be provided for pupils to better understand academic material and classroom instructions (PaulBrown, 1992). Viewed functionally, speech-language therapists are not "re-mediating" or "re-habilitating" communication, language and learning disabilities, but are attempting to proactively assist in the mediation of a school communication system for them. In this way, the passive reactive incrementalisation of existing facts can be replaced by the active recreation of knowledge.

Learning environments need to be ecologically congruent and authentic withian emic perspective, in order to facilitate effective language, learning and communication The majority of learning needs to be contextually embedded as realistically as is possible (Johnson, 1987). This is because "the brain is actually very poor at learning large amounts of material from books. It is naturally good at learning in the locations and circumstances of everyday life" (Jensen, 1995: 333). Knowledge is more easily reconceptualised into useful knowledge that can be utilised when it is associated with a novel experience, or location or feeling, or some type of hook that will tie it in with the content. Therefore neither the traditional "stand and deliver" context of teaching nor the isolated 1:1 therapy model are authentic, ecologically congruent or emic as the focus is on the teacher and therapist delivering content or remediating an identified "deficit". Rather, the learner needs to be guided to discover the meaning of the content. Furthermore, language, learning and communication are active creative processes. Whether the focus is on speaking, listening, reading, or writing, language and communication involve the creation of meaning and making sense (King \& Goodman, 1990). A curriculum or therapeutic approach that fragments language, communication and learning into small, abstract pieces with the expectation that if the parts are mastered, the whole will eventually be mastered, inhibits learning and communication (Schory, 1990). The opposite perspective is a whole lan- guage perspective where the learning direction is from the whole to the parts, (King \& Goodman, 1990; Schory, 1990 ), and therefore falls within the realms of a geodesic approach.

According to Schory (1990), children pass a crucial test, before school, suggesting that they are spontaneously proficient learners, because they master in a few years one of the most complex systems of rules known, their mother tongue. They also become quite proficient in the knowledge of the world around them (Iran-Nejad, 1990). By contrast, "only a few children in school ever become good at learning in the way we try to make them learn. Most of them get humiliated, frightened and discouraged. They use their mind, not to learn, but to get out of the things we tell them to do - to make them learn" (Holt, 1964: vii). Bereiter (1985, in Iran-Nejad, 1990) indicates that there is a complex relationship between the multisource nature of learning and the environment in which this learning is fostered. A young child's learning environment is multisource, creative and natural with the various sources that contribute, operating simultaneously. It facilitates a balance between active and dynamic self-regulation to occur.

This is in contrast to the less than authentic traditional learning environments of later life that foster a climate of encoding facts in an increasingly analytic and sequential way. This fosters an over-reliance on untrained or incorrectly-trained active self-regulation at the expense of dynamic self-regulation, which results in training children out of the natural way of learning (Holt, 1964, in Iran-Nejad, 1990). Therefore, the more wholistic, natural and meaningful the learning environment, is the more ecologically congruent and authentic it will be. This will ultimately result in more effective language, learning and communication skills.

Educationalists and therapists have a responsibility to change learning environments such that predominantly dynamic self-regulation operates with active self-regulation playing a minor role (Iran-Nejad, 1990; King \& Goodman, 1990; Schory, 1990). This can be done by applying the principles of the philosophy of geodesic learning which have authentic ecological environments built into their methodology.

Geodesic approaches have to have authentic learning environments in order to work. By adopting geodesic approaches such as the MMA, the practical application of the geodesic model, authentic learning environments will automatically be created. Further research is needed to explore geodesic learning environments that foster a climate of authentic learning. In summary, transformation of learning in the in the schools of the future will need to consider the neuropsychological aspects that allow the interaction of dynamic and active self-regulation which will facilitate innovative learning.

Learning is a process of active research initiated and controlled by the learner.

Learning as a process of active research means that one's learning intentions need to be changed from those aimed at optimizing the conditions for encoding and retrieval under other-regulation to optimising the conditions for understanding and personal growth under selfregulation (Iran-Nejad, 1990). The latter implies that cooperation between teachers, therapists and pupils is required in the development of any course or therapy purporting to meet their needs. Thus the learners take 
responsibility for their learning and the quality of their work in co-operation with the facilitator (Glasser, 1986). This is in contrast to traditional philosophy of education and institution-based rehabilitation (IBR) which identifies the teacher and therapist as being solely responsible for what is learned, and how, when, why and if it is learned.

Currently, however, in the field of Speech-Language Pathology, there is a move away from institution-based rehabilitation to community-based rehabilitation as a result of the increasing awareness of the inefficiency of traditional approaches, and the recognition of the social interactive nature of language (Paul-Brown, 1992). This is evident in the whole body of literature on alternative service delivery models designed to meet more efficiently the needs of clients with communication, language and learning problems (Paul-Brown, 1992; Lewis, 1994; Schory, 1990; King \& Goodman, 1992).

If learners are guided into taking responsibility for their learning, then this will lead to learning that is based on curiosity, need and relevance, and thus the motivation becomes intrinsic. Hence, the classroom and therapy room becomes focused on learning and not maintaining control. Teachers and therapists have authority, and are content specialists, but learners also have the right to be respected and given an opportunity to learn. According to Jensen (1995) and Iran-Nejad (1990), students in a fullyimplemented geodesic learning environment will rarely have behavioural, motivational and learning problems because they are fully engaged, curious, engrossed, challenged and excited about learning.

Students need to play a major role in the decision about what they have to learn and how this can be done; that is, learners need to take a higher level of responsibility for their own learning (Schory, 1990; King \& Goodman, 1990). Thus the learner needs to self-monitor and self-evaluate with the facilitator, with the emphasis on teaching the student how to assess the process and not just the end result of the process, the product (Glasser, 1986). The learners and facilitators should engage in continual constructive examination of how to improve the process of learning. This can be done by the teacher and/or speech-language therapist orally making decisions and solving problems concerning her own reading, writing, communication or learning activity in order to demonstrate the problem-solving process (Schory, 1990). This is especially important for the language-learning disabled students who frequently experience difficulty solving problems related to language, learning and communication (Damico, 1987).

Finally, comparative studies should be conducted between self-regulated students in geodesic environments and other-regulated students in traditional environments in terms of problem-solving, research skills, thinking skills and general life skills in order to compare the differences in performance and learning potentials. There is research of this nature in the literature, but concerning predominantly suggestopaedic techniques (Dhority, 1990; Lozanov, 1978). There are, however, relatively few programmes that offer the unique combination of the MMA, and it is felt that geodesic methods need to be used as wholistically as possible within a system's theory approach as opposed to componentially within a traditional approach to education. Thus, true geodesic systems need to be created and studied scientifically in order to create the body of evidence that is lacking in traditional learning approaches. Furthermore, this body of evidence will underscore the pitfalls of the traditional environments in education and therapy that were created, with relatively minimal scientific basis, (Gardner, 1985: Jensen, 1995; Iran-Nejad, 1990; Knowles, 1990), as well as supporting the intimation made by Gerber (1987) that traditional environments. "de-educate" students turning them into rote-learning "junkies".

In addition, the speculation that behavioural, motivational and learning problems will decrease in fully operating geodesic systems (Jensen, 1995; Iran-Nejad, 1990) needs scientific and documented research as this has profound implications for students. This is because the ability to take a proactive role in initiating and controlling the learning process allows personal effort and ability to take on a determining role. According to Glasser, (1986) persons who see themselves in control of a given situation make a greater effort to achieve success then those who do not. Language-learning disabled pupils in particular need to be allowed to have a sense of control over their own learning processes in order to overcome the passiveacceptant and learned helplessness that comes from repeated failure and being continually guided (Feuerstein, 1980). When a teacher or therapist continually: corrects and guides students' efforts, they prevent them from taking charge of their own learning. This leads to overdependency on others and decreased confidence in one's own abilities (Marvin, 1987). Thus, the languagelearning disabled child needs to be shown how and allowed to take control of the language, learning and communication situation in and out of school.

Intelligence is pluralistic and in every individual there is a unique blend that determines their individuality. The multiple intelligence theory (Gardner, 1985) challenges the prevailing concept of intelligence as a single general capacity that enables individuals to perform in all situations. According to Gardner (1985) every normal human being is born with seven different intelligences. Of these, one will be dominant and one secondary and this contributes to individualistic learning styles. If this does not conform to the dominant traditional teaching style, which emphasises verbal and mathematical intelligence, then individuals are at a disadvantage.

Thus, learning environments and facilitators need to recognise that intelligence is made up of different capacities, not just mathematical and linguistic, which results in a diversity of learning styles requiring highly individualised programmes and consequently, "freedom within structure". Furthermore, I.Q. testing, which is based on the single unitary concept of intelligence, cannot predict or determine potential as these tests are based on mathematical and linguistic intelligences alone. I.Q. testing can only predict how well a student can play the "school game", and may erroneously label a student, limiting aspirations.

Successful teaching and therapy need to reinforce and affirm the different ways in which individuals learn. Facilitators of learning need to incorporate situations where students have opportunities for the creative exploration of their individual interests and talents while also learning valued skills and concepts through multimodal means. Information needs to be presented in numerous ways offering students many opportunities to succeed. Therefore, manipulation and actual experience, moving, 
touching and doing should be part of the learning process. Learning environments need to help students to identify their areas of strength and to develop these so that they can become active contributors in society in their future. The more authentic the environment, the more effective the generalisation of skill mastery and problem-solving performance will be. In addition, learning is more effective if a process (for example: learning plan) and openended product structure (for example: therapy objectives, course outline) is applied, as opposed to a close-ended (traditional) product structure alone. Within the field of speech-language pathology, the whole-language approach (Schory, 1990) is evidence of this idea being practiced. The suggested geodesic methodology provides a broader framework enabling neuropsychological concepts to be incorporated into the whole-language approach, enhancing its effectiveness.

The practical application of facilitating the seven different intelligences in learning environments is currently available in the literature (Campbell et al., 1992, in Leaf 1997). What is needed is scientific research incorporating these applications into geodesic frameworks such as the MMA, and into learning environments in order to demonstrate their success.

The learning approach needs to be transdisciplinary requiring facilitators, directors and therapists to assume interchangeable roles and responsibilities following the needs of the child, the family and the community

A geodesic approach requires pupils, therapists, teachers and parents to commit to teaching and learning from each other by working together. This approach involves a collaborative and consultative methodology and as such, can be considered transdisciplinary (Thurman \& Widerstrom, 1990). A transdisciplinary approach falls within the realms of systems theory which allows any social system to be conceptualised as a system of learning resources, or an interdependent learning community (Knowles, 1990). A wholistic learning system is a complex of elements in mutual interaction.

Therefore, to account for wholism and interdependence, there has to be co-operative interaction between all the people within the system. The key issue, however, is the interchangeability of roles required and hence a transdisciplinary as opposed to interdisciplinary approach is essential for a truly geodesic learning environment to be created.

In order to operationalise the above implication, collaborative and consultative skills have to be included in any training of teachers and therapists (all types) (Simon, 1987). This would also include systems theory training which emphasises community-based learning systems. Future research needs to explore the benefits of transdisciplinary principles within wholistic geodesic learning environments such as those created when using the MMA, specifically the advantages of such an approach to the community as a whole. Resources are readily available in every environment, and thus a primary research focus is to identify these and introduce learners to them. Systems need to be put into effect where all resources within a community are explored and utilised in an organised interactive way within a geodesic framework. It is now recognised that services are most successful when teams of professionals and families collaborate forming partnerships. A transdisciplinary approach involves a collaborative consultative methodology involving both professionals and the community.

Teachers and therapists play different roles in a geodesic as opposed to traditional learning environments Historically, the classroom teacher provided the student with the curriculum material to be learned, and the speech-language therapist provided the student with remediation strategies for specified communication difficulties (Simon, 1987). However, the most important objective of a geodesic model such as the MMA is adapting the child's academic instruction so that he can achieve to the best of his ability. Many students are not successful learners and the differences between the educational experiences of students from different racial, linguistic and socio-economic backgrounds has led to many revisionist movements, which fall within the realms of geodesic philosophy, and which share the common goal of changing what does not appear to work. One direct result of this change is the re-discovery of the role language-proficiency plays in the education process (Simon, 1987). Here, the speech-language therapist, who is a language expert, can be extremely effective in mainstreaming into the classroom. This implies changed roles for both the speech-language therapist and the teacher who would need to work together in a consultative and collaborative manner in order to take advantage of their combined expertise. This whole-language approach (Schory, 1990) would change the focus from the identification and fixing of deficits to the purpose and nature of learning.

A teacher or therapist in a geodesic learning environment is a facilitator of learning. This implies that teachers and therapists are managers of the process of learning as opposed to content-transmitters. Being a content resource or a content specialist should be a secondary role to that of being a facilitator of learning. According to Knowles (1990) and Glasser (1986), being a process manager as opposed to a content planner and transmitter requires relationship building, needs assessment, involvement of students in curricular planning, linking students to learning resources and encouraging student initiative. This idea is developed within the whole-language approach (Schory, 1990; King \& Goodman, 1990) which provides a distinct philosophy as well as practical ideas on how to implement Glasser (1986) and Knowles' (1990) postulations.

In order to operationalise the different roles of the teacher and therapist within the geodesic environment, classroom and curriculum-based models which utilise the concepts of collaboration and consultation have to be developed. Classroom-based language and communication intervention has the distinct advantage of allowing the speech-language therapist to use the pupils' academic programmes as the basis upon which to build language intervention because pupils can stay in their classrooms and thus be present when important content information is given (Schory, 1990). Under such a system, known as the whole-language approach (Schory, 1990), the speechlanguage therapist would be able to monitor the development of oral language skills within a more natural setting than a therapy room; there could be a more frequent exchange of information between the teacher and speechlanguage therapist regarding the specific needs of each language-learning disabled child resulting in improved 
language-learning experiences; there would also be the opportunity to provide teachers with suggestions for incorporating all the varied forms of oral language within their lessons; the speech-language therapist could mediate the communicative interaction between the teachers and pupils; and finally the speech-language therapist could assist in the implementation of the MMA methodology initially as an expert consultant, and thereafter as a partner in a collaborative process. In this way the teacher and therapist together become facilitators of language, communication and learning.

In summary, a facilitator of learning allows learners to work, learn and grow at their own pace, not according to the teachers' and therapists' preset time-table. The facilitator will allow for new and different ways to solve problems without the traditional limits. The facilitator will supply the resources that will enable the learner to find the meaning enabling them to focus on the process and not the product.

The so-called "language-learning disabled population" can become innovative thinkers if their learning is facilitated within a geodesic environment using geodesic methodology

Recognising the possible neurological constraints of the language-learning disabled population, it is believed that within environments using geodesic frameworks such as the MMA many of the problems of the language-learning disabled pupil can be overcome enabling them to become innovative lifelong learners. Research (Jensen, 1995; Buzan, 1991; Dhority, 1991; Gardner, 1985) suggests that the brain thrives on novelty, challenge and enrichment, and therefore it is only logical and fair to put all types of learners into an environment that takes advantage of the natural functioning of the brain. According to Feuerstein (1980), restricting the level of requirements of the language-learning disabled child by simplifying the environment and reducing challenges, will lower levels of motivation, aspiration and achievement. Thus, in order to empower children with language-learning disabilities to reach higher levels of development, the traditional passive-acceptant approach must be replaced by an active approach to learning. According to this approach, the individual is an open system capable of mental and emotional modifiability. Therefore, low levels of achievement are reversible and it is possible to learn efficiently if the proper effort is invested in diverse and integrated ways (Feuerstein, 1980; Jensen, 1995; Gardner, 1985).

In order to operationalise this implication, learning environments need to change, from being passive-acceptant to active-modification. Entire new global systems need to be created that will allow all learners, whether language-learning disabled or not, to develop their potential together. A geodesic system of learning will focus on individuals and developing them; and not on fitting the individual into a system. Separate schools for learning disabled students are not necessary, they are in fact making the situation worse. Individual help can be given when required, but within the system. Therefore the child with language-learning disabilities should be mainstreamed and not protected within isolated educational frameworks (Simon, 1987). According to Feuerstein (1989: 166), "the ultimate purpose is to bring him satisfaction, not by isolating him and avoiding confrontation, but rather by providing tools for the daily struggle with a normal environment in which he may achieve satisfaction". The philosophy of the geodesic information processing model, and its practical application, the MMA, which is an active modification approach, has faith in the exceptional child's ability to change and grow, and accordingly great effort is invested in offering him many choices, as well as providing "tools" for change for example: the Mind-Map and the MMA strategies.

In addition, a system of "pull-out" programmes within the mainstream (Simon, 1987) could be created for students with. special needs. Instead of the traditional approach which primarily teaches content more slowly, these should focus on the processes and values of learning, for instance, how to spell, rather than lists of rote spelling words; how to learn; Mind-Mapping; communication skills; and finally social skills (Jensen, 1995).

\section{Learning in a world of continuing accelerating change is a process of ongoing enquiry}

Within the field of Speech-Language Pathology and Audiology, the increased awareness of the inefficiency of traditional approaches has led to the emergence of alternative treatment approaches. The alternative service delivery models (Paul-Brown, 1992) have been the result of speech-language therapists being required to serve a wider range of persons who present with a greater variety of communication disorders (Lewis, 1994). This has resulted in a paradigm shift in the professional self-concept of and role played by the speech-language therapist.

This necessitates the ability to learn to understand, guide, influence and manage these transformations or paradigm shifts. Learning activity should be deformalized and replaced by flexible diversified models, such as the MMA, based on the geodesic information processing model, in order to move learning into the twenty-first century (UNESCO, 1972, in LTFA, 1996). It therefore becomes an imperative task for individuals, institutions and society as a whole to learn about the process of learning

In the attempt to overcome the maintenance effects of conditioned traditional paradigms, and to foster a climate of change, as well as to deal with the education and therapy crises, it is believed that the basic training of therapists and teachers needs to change to adopt a geodesic philosophy which allows for more flexible and diversified models to be created and implemented. The training of facilitators and pupils or learners within geodesic philosophies such as the MMA has to aim at changing attitudes in order to create global changes in traditional learning philosophies. This will have long-lasting effects on the skill level of application in teachers and therapists and their pupils and clients, and by implication, on the educational and therapeutic environments in which learning is facilitated.

Furthermore the institution of training programmes to achieve the objective of creating global changes to geodesic systems for education and therapy needs to recognise the complex interrelationship between the diverse institutional learning environments in order to be successful. If the philosophy of systems theory (von Bertalanaffy, 1968 in Leaf, 1997), which visualises the complex interaction of systems and sub-systems, is adopted, then geodesic frameworks such as the MMA could be applied with- 
in the larger framework of lifelong learning. The systems theory could therefore provide the principles of creating infrastructures within which geodesic frameworks could be implemented for education and therapy on all levels of learning. For instance Knowles (1990) visualises an infrastructure for a lifelong learning resource system based on systems theory that emphasises the need to teach the community as a whole how to learn. The role of geodesic frameworks such as the MMA in such an infrastructure is that of providing the "how" of the implementation of facilitating geodesic learning environments.

Thus, the systems theory (von Bertalanaffy, 1968 in Leaf, 1997) provides the infrastructure for the creation of geodesic learning environments, and programmes such as the MMA provide the methods of training and facilitation within the geodesic learning environment. It is proposed that future research should concern itself with the interaction of the creation of geodesic infrastructures and the programmes providing the methods of facilitating geodesic learning. Therefore the results of this study, and those of other similar research, need to be integrated with systems theory to create long-term and long-lasting changes that will ultimately equip learners with innovative lifelong learning skills.

Further research regarding the manner in which the attitudes of teachers, therapists, parents, pupils, and all those conditioned in to the traditional system can be enlightened in order to change their perceptions of their roles as learners.

\section{The purpose of "educating" and "remediating" is to facilitate innovative life skill learning competen- cies}

Students should be excited about learning as it is a natural neuropsychological law that the brain is designed to learn. In a geodesic environment, students learn about life, they learn from each other, they learn what is in the curriculum and in therapy objectives, and they are ready to become lifelong learners that can contribute to society By applying geodesic philosophies, lifelong learning competencies can be developed. The geodesic information processing model and the practical application, the MMA, focuses on the learner, not the content. The organisation of lesson and therapy objectives within the MMA is based around creating condition's optimal for learning. It allows immersion into an integrated, thematic and interdisciplinary curriculum. This is in contrast to traditional formats of education and institution type therapy that emphasize learning one thing at a time so that a subject is divided into small chunks, and then sub-divided again and again. Each day a micro chunk of the whole is presented out of context, for instance, "introduce unit A, learn it, take a test on it; now go to unit B" (Jensen, 1995: 301). Rather should one learn in an integrated thematic way. According to Jensen (1995: 303), "our brain is designed to learn multi-path, in order, out of order, on many levels, with many teachers, in many contexts and from many angles. We learn with themes, favourite subjects, issues, key concepts, questions, trial and error and application. The thematic approach urges you to follow threads that weave through your student's world instead of a single subject or text book". This is the philosophy of the geodesic information processing model. The actual structure of the Mind-Map, the "tool" of the MMA, promotes this type of thinking because it creates patterns of meaning. Therefore practical applications of geodesic philosophy such as the MMA provide a strategic approach that can assist in the facilitation of innovative learners with good life-skills.

\section{CONCLUSION}

The central thesis of the current paper is to change the perception of the traditional view of learning as a "mosaic of educational and therapeutic programmes conducted by a plethora of largely unconnected institutions" (Knowles, 1990:17), into a lifelong learning resource system or learning community. This implies that learning should be viewed as an internal construction process controlled by the learner, as opposed to the internalisation of external facts from an external source such as a therapist or teacher. The geodesic model is seen to provide an alternative approach or system as well as a theoretical base to the perception of learning. The geodesic information processing model is also an attempt to develop a theory to explain why a geodesic framework such as the MMA (not explained in this paper) invokes more effective thought processing than traditional behaviouristic approaches to education and therapy.

The key issue in the geodesic information processing model of the current research is the intimate interaction and interdependence of metacognition and neuropsychology. The model proposes that metacognition is the nonconscious level, elevating metacognition to the level where most learning (approximately $90 \%$ ) occurs. This is the highest level of thought, where thinking begins. The model then proposes that cognition is the next level of thought, the level of conscious thinking responsible for approximately $10 \%$ of learning. Both levels need to be fully activated according to the ratio of their responsibility in order for learning to be effective and result in usefully reconceptualised knowledge. If methodologies and systems are used that are incompatible with natural neuropsychological laws, then the cognitive level will be predominantly activated, with limited intermittent involvement of the metacognitive non-conscious level. This will result in inefficient rote-type learning with a product orientation as opposed to process orientation. It is believed that geodesic methodologies such as the MMA (Leaf, 1997), are neuropsychologically based and will thus activate metacognition and cognition in the correct way. In contrast, traditional methodologies stimulate predominantly cognitive processes with concomitant learning limitations. Furthermore, the Mind-Map itself is viewed as the "tool" which directly accesses and trains the metacognitive non-conscious. The emphasis of the MMA is on the facilitation of improved language, learning and communication through a strategic versus skill-based approach Communication, language and learning are seen as being controlled by metacognition, which will in turn influence information processing and thus the effectiveness of communication, language and learning - oral or written. In other words, strategies are being facilitated at the root level and once automatized, will have a more effective result in terms of generalisation than if fragmented skills are trained.

"Throughout history only a few people have benefited from the growing corpus of scientific knowledge which permits the development of human potential. Inequality 
of human beings was not determined genetically. They all have more or less the same potentiality, the same capacity to think" (Van der Vyver \& Capdeveille, 1990:6). Therefore, every effort should be made to develop this potential of individuals. Everyone should be allowed the opportunity to learn how to learn.

\section{ACKNOWLEDGEMENTS}

The current article is based on the D.Phil. research of C. Leaf. The financial assistance of the Centre for Science Development towards the research is hereby gratefully acknowledged.

\section{REFERENCES}

Allport, D.A. (1980). Patterns and Actions: Cognitive Mechanisms and Content Specific in Claxton, G.L. (Ed), Cognitive Psychology: New Directions. London: Routledge \& Kegan Paul.

Dhority, L. (1991). The ACT Approach: The Artful Use of Suggestion for Integrative Learning. Bremen, West Germany: PLS Verlag GmbH, An der Weide.

Diamond, M. (1988). Enriching Heredity: The Impact of the Environment on the Brain. New York: Free Press.

Feldman, D. (1980). Beyond Universals in Cognitive Development. Norwood, N.J.: Ablex Publishers.

Feuerstein, R. (1980). Instrumental Enrichment: An Intervention Programme for Cognitive Modifiability. Baltimore, Maryland: University Park Press.

Flavell, J.H. (1978). Metacognitive Development in Scandura J.M. \& Brainerd, C.J. (Eds) Structural / Process / Theories of Complete Human Behaviour. The Netherlands: Sijthoff \& Noordoff.

Gardner, H. (1985). Frames of Mind. New York: Basic Books.

Glasser, M.D. (1986). Control Theory in the Classroom. New York: Harper \& Row.

Goldberg, E. \& Costa, L.D. (1981). Hemisphere Differences in the Acquisition and Use of Descriptive Systems. Brain and Language, 14 144-173.

Hinton, G.E. \& Anderson, J.A. (1981). Parallel Models of Associate Memory. Hillsdale N.J.: Erlsbaum.

Holt, J. (1964). How Children Fail. New York: Pitman.

Iran-Nejad, A. (1990). Active and Dynamic Self-Regulation of
Learning Processes. Review of Educational Research, 60 (4) $573-602$.

Jensen, E. (1995). Brain-Based Learning and Teaching. South Africa : Process Graphix

Johnson, J.M. (1987). A Case History of Professional Evolution From SLP to Communication Instructor. Journal of Childhood Communication Disorders, 11 (4) 225-234.

King D.F \& Goodman, K.S. (1990). Whole Language Learning, Cherishing Learners and their Language. Language, Speech and Hearing Sciences in Schools, $21221-229$.

Kline, P. (1990) Everyday Genius. Arlington, V.A.: Great Ocean Publishers.

Knowles, M. (1990) The Adult Learner: A Neglected Species. Houston: Gulf Publishing Company.

Leaf, C.M. (1990). Mind-Mapping: A Therapeutic Technique for Closed Head Injury. Unpublished Masters Dissertation, University of Pretoria.

Leaf, C.M. (1997). The Mind Mapping Approach: A Model and Framework for Geodesic Learning. Unpublished D.Phil Dissertation, University of Pretoria.

Leaf, C.M., Uys, I.C. \& Louw, B. (1993). Mind Mapping: A Culture and Language Free Technique. South African Journal of Communication Disorders, 40 35-43.

Lewis, R. (1994). Report Back on the Workshop: Speech / Language / Hearing Therapy in Transition. Communiphon, 308 6-7.

Lozanov, G. (1978). Suggestology and Outlines of Suggestopedy. New York: Gordon and Breach Science Publishers.

Luria, A.R. (1980). Higher Cortical Functions in Man (2nd Ed). New York: Basic Books.

Paul-Brown, D. (1992). Professional Practices Perspective on Alternative Service Delivery Models. ASHA Bulletin, 12.

Schory, M.E. (1990). Whole Language and the Speech. Language Pathologists. Language, Speech and Hearing Services in Schools, 21 206-211.

Simon, C.S. (1987). Out of the Boom Closet and into the Classroom: The Emerging SLP. Journal of Childhood Communication Disorders, 11 (1-2) 81-90.

Thurman, S.K \& Widerstrom, A.H. (1990). Infants and Young Children with Special Needs A Developmental and Ecological Approach. 2nd (Ed) - Baltimore: Paul H. Brookes Publishing Co.

Van der Vyver, D.W. \& de Capdeveille, B. (1990). Towards the Mountain: Characteristics and Implications of the South African UPPTRAIL Pilot project. Journal of the Society for Accelerative Learning and Teaching, 15 (1 \& 2) 59-74. 


\section{EMPLOYMENT IN THE UK}

For a working holiday or permanent position,

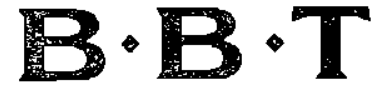

is second to none.

Join the hundreds of Speech and

Language Therapists we secure locum

and long term positions for each year. Our excellent reputation allows us to offer assignments throughout the UK, many of which are in the leading establishments in the state and private sectors.

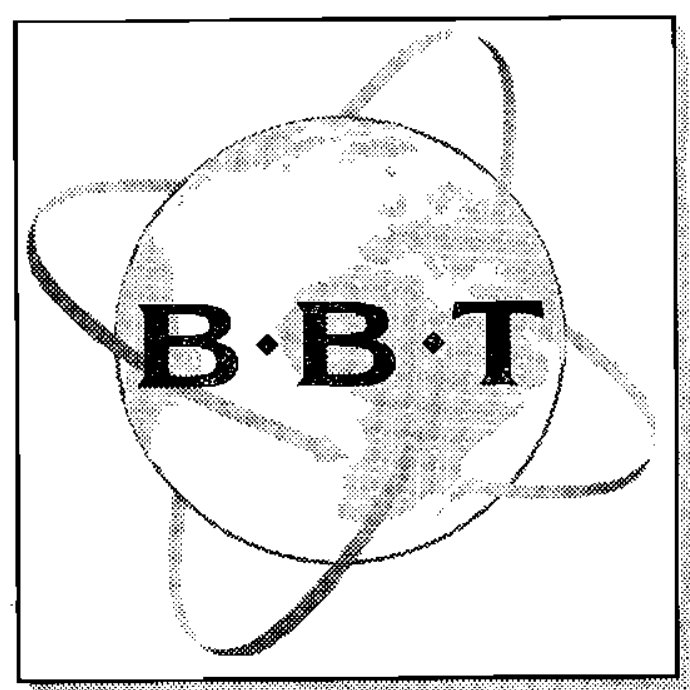

Our dedicated team can guide you through the registration procedures prior to arrival and once in the UK, provide you with all the support you require. You will find our experience invaluable in ensuring your time is a complete success and the overall package unbeatable.

Contact Sean Ridgwell in London today for an initial discussion and our frec information pack, or send your details, so that we can contact you.

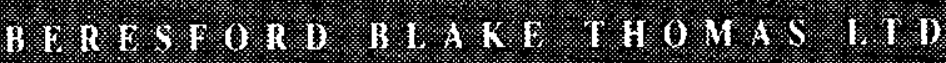

$$
\text { Toll free - } 0800998154
$$

Fax:09441712338004E-mail: recruit@bbt.co.uk 14 Buckingham Palace Road, London SW 1 W OQP, England. 
